\title{
A model chemosensitivity test examining apoptosis in small specimens of gastric cancer
}

\author{
Narikazu Boku, Atsushi Ohtsu, and Shigeaki Yoshida \\ Division of Digestive Endoscopy and Gastrointestinal Oncology, National Cancer Center Hospital East, 6-5-1 Kashiwanoha, Kashiwa, \\ Chiba 277-8577, Japan
}

\begin{abstract}
Background. Because chemosensitivity tests usually require a large amount of tissue, they are not used routinely in patients with unresectable gastric cancer. The aim of this study was to investigate whether apoptosis can be used as a sensitivity assay for chemosensitivity in small gastric cancer specimens. Methods. Apoptosis, detected by terminal deoxynucleotidyl transferase-mediated dUTP-biotin nick labeling (TUNEL), was investigated in small specimens of the MKN-1, MKN45, and TMK-1 human gastric cancer cell lines as a marker of chemosensitivity following exposure to antineoplastic agents. Results. Doxorubicin (DXR), SN-38 (active metabolite of irinotecan), and paclitaxel (Taxol) induced DNA fragmentation in MKN-45 and TMK-1 cells, but not in MKN-1. In contrast, neither 5-fluorouracil (5-FU) nor cisplatin (CDDP) induced DNA fragmentation in any of the three cell lines. Small pieces cut from tumors implanted in nude mice were exposed to the antineoplastic agents in culture medium for $24 \mathrm{~h}$, and the percentage of TUNEL-positive cancer cells (TUNEL positivity) was examined. TUNEL positivity in all three cancers increased after exposure to DXR, SN-38, and Taxol, but not after exposure to CDDP or 5-FU. MKN-45 showed the highest TUNEL positivity with SN-38 and Taxol, and TMK-1 TUNEL positivity was highest with DXR. MKN45 and TMK-1 were the most sensitive to these three antineoplastic agents in vitro, while MKN-1, with the lowest TUNEL positivity, was the least sensitive to these three antineoplastic agents. TUNEL positivity after exposure to Taxol correlated with the antitumor effects of this compound in an animal model.

Conclusion. These results suggest that, in small gastric cancer specimens where apoptosis is implicated, TUNEL positivity may be applicable to a chemosensitivity test.
\end{abstract}

Key words Chemosensitivity $\cdot$ Apoptosis $\cdot$ TUNEL $\cdot$ Gastric cancer $\cdot$ Small specimen

\section{Introduction}

Clinically, it is important to predict chemoresponse before initiating chemotherapy. Over the past few decades much research has been directed to the development of chemosensitivity tests [1-3], some of which can successfully predict chemoresponse clinically [4-7]. However, chemosensitivity tests are not used routinely because they are labor-intensive and time-consuming. Moreover, these tests are based on a comparison of the viability of treated and untreated cancer cells, and require a large amount of cancer tissue. It is difficult to obtain large samples of cancer tissue for chemosensitivity tests from patients with unresectable or recurrent cancer who are to undergo chemotherapy. Therefore, it is necessary to develop a chemosensitivity test that can be performed on small biopsy specimens.

Some antineoplastic agents (e.g., topoisomerase inhibitors, DNA reactive drugs, and antimetabolites) have been reported to induce apoptosis [8-13]. Apoptosis can be detected in small specimens by morphological changes, DNA fragmentation, and terminal deoxynucleotidyl transferase-mediated dUTP-biotin nick labeling (the TUNEL assay [14]). Although apoptosis correlates with chemosensitivity to some antineoplastic agents [15,16], a chemosensitivity test based on an examination of apoptosis has not yet been established.

The relationship between apoptosis and chemosensitivity was investigated in order to clarify whether apoptosis can be used as a sensitive assay for chemosensitivity. In this study, apoptosis was detected, using the TUNEL assay, in small specimens of human gastric cancers exposed to antineoplastic agents both in vitro and in animal model. 


\section{Methods}

\section{Cell culture}

The human gastric cancer cell lines, MKN-1 [17], MKN45 [17], and TMK-1 [18], were cultured in RPMI-1640 medium (Nissui Pharmaceutical, Tokyo, Japan) supplemented with $10 \%$ heat-inactivated fetal calf serum (GIBCO BRL, Tokyo, Japan), $4 \mathrm{mM}$ L-glutamine, $10 \mathrm{U} / \mathrm{ml}$ penicillin and streptomycin (culture medium) at $37^{\circ} \mathrm{C}$ in $5 \% \mathrm{CO} 2$ and $95 \%$ air.

\section{Antineoplastic agents}

Cisplatin (CDDP) and doxorubicin (DXR) were purchased from Daiichi Pharmaceutical (Tokyo, Japan), and 5-fluorouracil (5-FU) was purchased from Kyowa Hakko Kogyo (Tokyo, Japan). Paclitaxel (Taxol) and SN-38 (active metabolite of irinotecan) were kindly provided by Bristol-Myers Squibb (Tokyo, Japan) and Daiichi Pharmaceutical, respectively. Taxol, CDDP, 5FU, and SN-38 were stored at $4{ }^{\circ} \mathrm{C}$, and DXR dissolved in saline $(2 \mathrm{mg} / \mathrm{ml})$ was stored at $-20^{\circ} \mathrm{C}$ as a stock solution. Each of these agents was diluted with phosphatebuffered saline (PBS) immediately before use.

\section{Chemosensitivity in vitro}

The chemosensitivity of the gastric cancer cells in vitro was assessed by the concentration that inhibited cell growth by $50 \%\left(\mathrm{IC}_{50}\right)$. Briefly, MKN-1, MKN-45, and TMK- 1 cells were plated in 96 -well plates $\left(4 \times 10^{3}\right.$ cells/ well), and cultured for $24 \mathrm{~h}$. The antineoplastic agents were then added to triplicate wells $(200 \mu \mathrm{l} /$ well $)$; DXR, CDDP, SN-38, and Taxol were used at concentrations of 0 to $1.0 \times 10^{1} \mathrm{mg} / \mathrm{ml}$, and $5-\mathrm{FU}$ was used at 0 to $1.0 \times$ $10^{1} \mathrm{mg} / \mathrm{ml}$. After 72 -h culture, $10 \mu \mathrm{l}$ of 3-(4,5-Dimethyl-2thiazolyl)-2,5-diphenyl-2H-tetrazolium bromide (MTT) in phosphate-buffered saline (PBS; $0.5 \mu \mathrm{g} / \mathrm{ml}$ ) was added to each well (Sigma-Aldrich Japan, Tokyo Japan). (MTT was filtered through a $0.45-\mu \mathrm{m}$ filter membrane before use.) Four h later, the medium was aspirated carefully and crystals were dissolved by the addition of $200 \mu \mathrm{l}$ dimethyl sulfoxide to each well. Absorbance was then measured at $540 \mathrm{~nm}$, using an enzyme-linked immunosorbent assay (ELISA) reader. The $\mathrm{IC}_{50}$ of each antineoplastic agent was calculated for each cancer cell line.

\section{DNA fragmentation in vitro}

Cells $\left(1 \times 10^{5}\right)$ were plated in $10-\mathrm{cm}$ culture dishes and cultured for $24 \mathrm{~h}$. The culture medium was then replaced with fresh medium $(10 \mathrm{ml} / \mathrm{dish})$ containing antineoplastic agent at the following concentrations: DXR, CDDP, SN-38, and Taxol, 0, $1.0 \times 10^{-5}, 1.0 \times$ $10^{-4}, 1.0 \times 10^{-3}, 1.0 \times 10^{-2}$, and $1.0 \times 10^{-1} \mu \mathrm{g} / \mathrm{ml}$; and 5-FU, at $0,1.0 \times 10^{-3}, 1.0 \times 10^{-2}, 1.0 \times 10^{-1}, 1.0$, and 1.0 $\times 10^{1} \mu \mathrm{g} / \mathrm{ml}$. After treatment with the individual antineoplastic agent for $24 \mathrm{~h}$, both free and adherent cells were collected, the latter following trypsinization. Cells were collected by centrifuging at $3000 \mathrm{rpm}$. They were washed three times in PBS and lysed with $0.5 \mu \mathrm{g} / \mathrm{ml}$ proteinase $\mathrm{K}$ (Sigma) in lysis buffer $(0.5 \%$ sodium dodecylsulfate [SDS], $5 \mathrm{mM}$ ethylenediamine tetraacetic acid [EDTA], $10 \mathrm{mM}$ Tris- $\mathrm{HCl} \mathrm{pH} \mathrm{7.8)} \mathrm{at} 37^{\circ} \mathrm{C}$ for $24 \mathrm{~h}$. DNA was extracted with phenol/chloroform, precipitated with ethanol, dissolved in $10 \mathrm{mM}$ Tris- $\mathrm{HCl}$ ( $\mathrm{pH} 7.8$ ) and then treated with $0.5 \mu \mathrm{g} / \mathrm{ml}$ RNAse A (Sigma) at $37^{\circ} \mathrm{C}$ for $1 \mathrm{~h}$.

DNA was electrophoresed $(20 \mu \mathrm{g} / \mathrm{lane}, 100 \mathrm{~V}, 20 \mathrm{~min})$ in $2 \%$ agarose gel containing ethidium bromide $(0.5 \mu \mathrm{g} /$ $\mathrm{ml})$. DNA fragmentation was visualized by UV illumination, and the minimum concentration of each antineoplastic agent required to induce DNA fragmentation (MCIDF) was determined for each cell line.

\section{Drug treatment of small tumor pieces}

Cancer cells $\left(1 \times 10^{7}\right)$ were implanted subcutaneously in 4-week-old female BALB/c nu/nu nude mice (Charles River Japan, Yokohama, Japan). Four weeks later, when the tumors had grown to larger than $1 \mathrm{~cm}$ in diameter, the viable part of each tumor was aseptically resected, and then dissected into small pieces of approximately 2-mm diameter. The small tumor pieces were exposed for $24 \mathrm{~h}$ to the antineoplastic agents added to culture medium at the following concentrations: DXR, CDDP, SN-38, and Taxol, at 0, $1.0 \times 10^{-5}$, $1.0 \times 10^{-4}$, and $1.0 \times 10^{-3} \mathrm{\mu g} / \mathrm{ml}$; and 5-FU, at $0,1.0 \times$ $10^{-3}, 1 \times 10^{-2}$, and $1 \times 10^{-1} \mu \mathrm{g} / \mathrm{ml}$.

\section{TUNEL positivity in small tumor pieces}

Small tumor pieces, either untreated or treated with antineoplastic agents, were fixed with $10 \%$ formalin overnight and embedded in paraffin. Five specimens were aligned in paraffin according to the concentrations of the antineoplastic agent. Four- $\mu$ m-thick slices were cut from each block, deparaffinized in xylene, and hydrated in graded concentrations of ethanol. After being washed with $100 \mathrm{mM}$ Tris- $\mathrm{HCl}$ at $\mathrm{pH} 7.8$, sections were immersed in methanol containing $0.3 \% \mathrm{H}_{2} \mathrm{O}_{2}$ for $20 \mathrm{~min}$ to inhibit endogenous peroxidase activity. The sections were rinsed thrice with distilled water for $2 \mathrm{~min}$ each time, and then treated with $10 \mu \mathrm{g} / \mathrm{ml}$ proteinase $\mathrm{K}$ in lysis buffer at $37^{\circ} \mathrm{C}$ for $10 \mathrm{~min}$. The sections were then immersed in terminal deoxynucleotidyl transferase (TdT) (0.3 e.u./ml) (GIBCO, Grand Island, NY, USA) and biotinylated dUTP $(0.04 \mathrm{mmol} / \mathrm{ml})(\mathrm{GIBCO})$ in TdT buffer $(0.1 \mathrm{M}$ potassium cacodylate, $\mathrm{pH} 7.2,2 \mathrm{mM}$ cobalt chloride, $0.2 \mathrm{mM}$ dithiothreitol) (GIBCO) in a humid atmosphere at $37^{\circ} \mathrm{C}$ for $90 \mathrm{~min}$. The reaction was 
terminated by transferring the sections to a stopping buffer ( $300 \mathrm{mM} \mathrm{NaCl}, 30 \mathrm{mM}$ sodium citrate) for $15 \mathrm{~min}$ at room temperature.

After being washed thrice with PBS for 2 min each time, sections were incubated in Avidin Biotin Complex (ABC) reagent (Vector Laboratories, Burlingame, CA, USA) for $1 \mathrm{~h}$. The color reaction was developed in $2 \%$ 3-3'-diaminobenzidine (Sigma) and $0.3 \% \mathrm{H}_{2} \mathrm{O}_{2}$ in Tris buffer, and the sections were counterstained with methyl green. Cancer cells were distinguished morphologically from stromal cells by microscopic examination $(\times 400)$ and the percentages of TUNEL-positive cancer cells (TUNEL positivity) were calculated by scoring about 3000 cells in each specimen (five visual fields/ specimen). DNA fragmentation in each small specimen treated with antineoplastic agents was also examined, using methods for examining DNA fragmentation in vitro.

\section{Antitumor effect of Taxol in an animal model}

Taxol $(9 \mathrm{mg} / \mathrm{kg}$ per day) was injected intraperitoneally for 9 consecutive days, beginning 4 weeks after the implantation of MKN-1, MKN-45, and TMK-1 into nude mice (three mice/cell line). The same volume of PBS was injected in a similar manner as a control. The length "a" and width "b" (in $\mathrm{mm}$ ) of each tumor was measured every 3 days from the first injection to day 12 . Tumor weight was calculated as $0.5 \times \mathrm{a} \times \mathrm{b}^{2}(\mathrm{mg})$. The relative growth compared with tumor weight on day 0 and relative tumor weight to the control $(\mathrm{T} / \mathrm{C})$ were calculated.

\section{Results}

$I C_{50}$ and minimum concentration inducing DNA fragmentation (MCIDF)

DXR, SN-38, and Taxol induced DNA fragmentation in MKN-45 and in TMK-1 cells, but not in MKN-1. In contrast, 5-FU and CDDP did not induce DNA fragmentation in any of these gastric cancer cell lines. The relationship between in-vitro chemosensitivity $\left(\mathrm{IC}_{50}\right)$ and MCIDF for DXR, SN-38, and Taxol is shown in Table 1. The MKN-1 cells did not show DNA fragmentation and had the lowest sensitivity to these three antineoplastic agents. For DXR, the $\mathrm{IC}_{50} \mathrm{~s}$ and MCIDFs of MKN-45 and TMK-1 were similar. For SN-38 and Taxol, the $\mathrm{IC}_{50} \mathrm{~s}$ and MCIDFs of MKN-45 were lower than those of TMK-1.

DNA fragmentation and TUNEL positivity in small pieces of tumors left untreated

Fewer than $1 \%$ of cancer cells in the small tumor pieces fixed immediately after resection showed TUNEL-
Table 1. $\mathrm{IC}_{50}$ and minimum concentrations inducing DNA fragmentation

\begin{tabular}{llcc}
\hline Drug & Cell line & IC $_{50}$ & MCIDF \\
\hline DXR & MKN-1 & $2.3 \times 10^{-2}$ & ND \\
& MKN-45 & $1.1 \times 10^{-2}$ & $1 \times 10^{-5}$ \\
& TMK-1 & $9.2 \times 10^{-3}$ & $1 \times 10^{-5}$ \\
SN-38 & MKN-1 & $4.5 \times 10^{-2}$ & ND \\
& MKN-45 & $3.2 \times 10^{-3}$ & $1 \times 10^{-4}$ \\
& TMK-1 & $1.7 \times 10^{-2}$ & $1 \times 10^{-2}$ \\
Taxol & MKN-1 & $3.0 \times 10^{-2}$ & ND \\
& MKN-45 & $7.1 \times 10^{-3}$ & $1 \times 10^{-4}$ \\
& TMK-1 & $2.7 \times 10^{-2}$ & $1 \times 10^{-3}$ \\
\hline
\end{tabular}

DXR, Doxorubicin; SN-38, active metabolite of irinotecan; Taxol, paclitaxel; $\mathrm{IC}_{50}(\mu \mathrm{g} / \mathrm{ml})$, concentration of each antineoplastic agent that inhibited the growth of cancer cells by $50 \%$ in vitro; MCIDF, minimum concentration $(\mu \mathrm{g} / \mathrm{ml})$ of an antineoplastic agent that induced DNA fragmentation in vitro; ND, DNA fragmentation was not detected

Table 2. Percentage of TUNEL-positive cancer cells in small tumor pieces immediately after resection and after 24-h culture

\begin{tabular}{lcc}
\hline & \multicolumn{2}{c}{ TUNEL (\%) } \\
\cline { 2 - 3 } Tumor & Immediately & 24-h Culture \\
\hline MKN-1 & $0.8 \pm 0.6$ & $0.7 \pm 1.0$ \\
MKN-45 & $0.1 \pm 0.1$ & $0.9 \pm 1.3$ \\
TMK-1 & $0.5 \pm 0.3$ & $2.2 \pm 2.8$ \\
\hline
\end{tabular}

TUNEL, Terminal deoxynucleotidyl transferase-mediated dUTPbiotin nick labeling

positive cells. TUNEL positivity was detected in fewer than $3 \%$ of cancer cells following culture for $24 \mathrm{~h}$ in medium containing no antineoplastic agents (Table 2). However, untreated specimens of all three cancers showed DNA fragmentation after 24-h culture.

\section{TUNEL positivity in small tumor pieces}

The percentages of TUNEL-positive cells in all three cancers increased after 24-h treatment with DXR, SN-38, or Taxol. The relationship between TUNEL positivity and $\mathrm{IC}_{50}$ for each of these three gastric cancers is shown in Fig. 1.

Although the percentages of TUNEL-positive cells were dose-dependent, in some cases, estimations of the percentages of TUNEL-positive cells at three different concentrations of the antineoplastic agent were consistent with the degree of apoptosis induced in the cancer cell line. TMK-1 had the highest percentage of TUNEL-positive cells after DXR treatment, and MKN45 had had the highest percentage of TUNEL-positive cells after SN-38 and Taxol treatments. TUNEL positivity correlated with $\mathrm{IC}_{50} \mathrm{~s}$. None of the three 
(C)
(A)

(B)
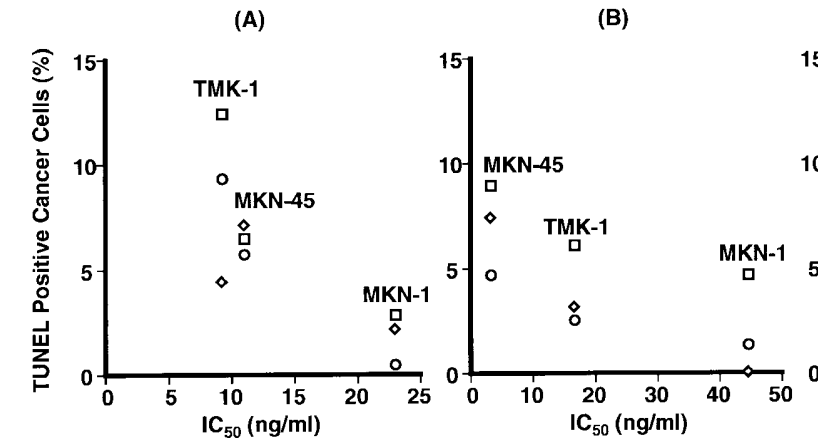

Fig. 1A-C. Percentages of terminal deoxynucleotidyl transferase-mediated dUTP-biotin nick labeling (TUNEL) positive cancer cells and concentration of neoplastic agent that inhibited the growth of cancer cells by $50 \%$ in vitro $\left(I C_{50}\right)$. The $\mathrm{IC}_{50} \mathrm{~S}$ for the cancer cell lines MKN-1, MKN-45, and TMK-1 of A doxorubicin (DXR), B active metabolite of

gastric cancer cell lines showed an increase in the percentage of TUNEL-positive cells after treatment with either CDDP or 5-FU, and TUNEL positivity did not correlate with the $\mathrm{IC}_{50}$ for these two agents (data not shown).

\section{Chemosensitivity to Taxol in an animal model}

Figure 2 shows the relative tumor growth of the gastric cancers implanted in nude mice after intraperitoneal injection of Taxol. This reflects the sensitivity of these three cancers to Taxol in an animal model. Mice implanted with MKN-45 showed a decrease in tumor weight. The relative weights of tumors in comparison with the control (T/C) on day 12 were 0.67 for MKN-1, 0.33 for MKN-45, and 0.78 for TMK-1.

\section{Discussion}

Chemosensitivity tests in which cancer cells are exposed to antineoplastic agents in suspension are said to fail to mimic in-vivo conditions. Recently, it has been reported that histoculture allows specimens to maintain cell-tocell contact and interaction, and succeeds in mimicking the conditions of drug exposure in vivo [3]. Kubota et al. [5] reported the clinical utility of a histoculture drug response assay in which small tumor pieces were cultured on a sponge gel support for 7 days. In the present study, small tumor tissue specimens preserving cell-tocell contact were cultured for $24 \mathrm{~h}$. TUNEL positivity in untreated specimens was less than $3 \%$ (Table 2). Shortterm culture of untreated tumor specimens may account for the low percentage of TUNEL-positive cells. Shortterm culture of tumor specimens does not appear to induce significance apoptosis. irinotecan (SN-38), and $\mathbf{C}$ Taxol are shown. Percentages of TUNEL-positive cancer cells in small pieces of cancers cut from tumors implanted in nude mice after exposure to the antineoplastic agents for $24 \mathrm{~h}$ at concentrations of $1.0 \times$ $10^{-5}$ (circles), $1.0 \times 10^{-4}$ (diamonds), and $1.0 \times 10^{-3} \mu \mathrm{g} / \mathrm{ml}$ (squares), are shown

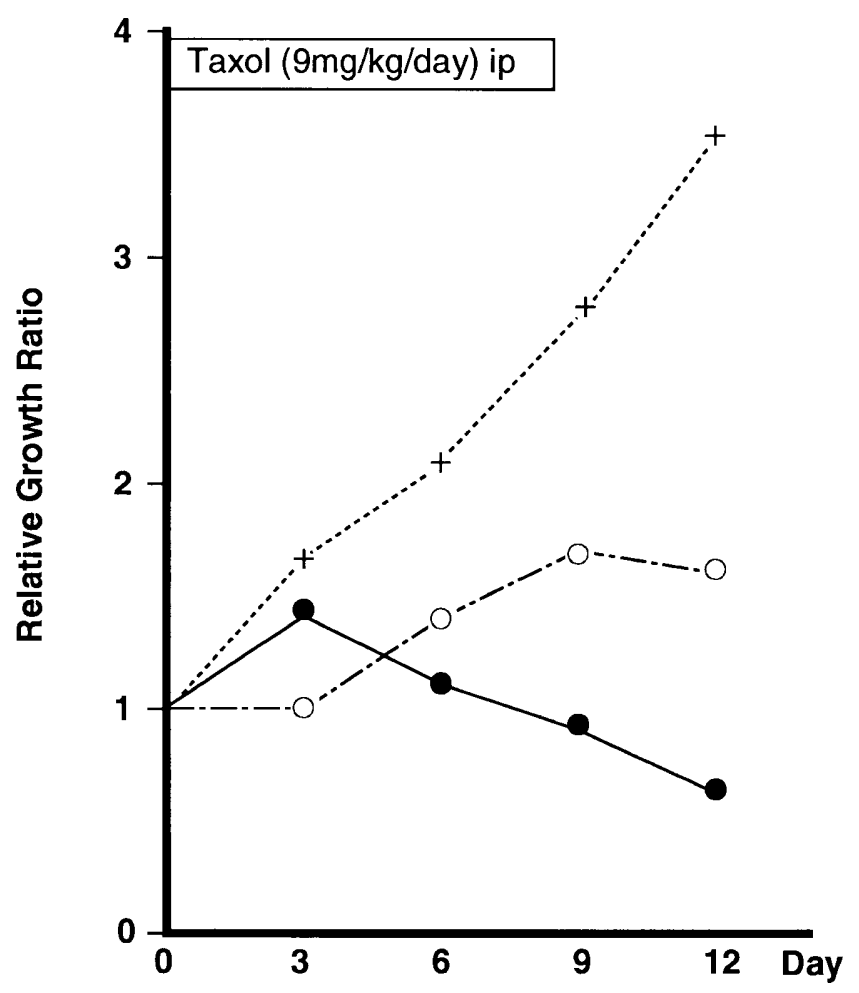

Fig. 2. Antitumor effects of Taxol in an animal model. Relative tumor growth of MKN-1 (circles), MKN-45 (dots), and TMK-1(crosses) after intraperitoneal (ip) injection of Taxol $(9 \mathrm{mg} / \mathrm{kg}$ per day) for 9 days was calculated by comparison with weight on day 0

In this study, MKN-1 did not show DNA fragmentation and was the least sensitive of the cell lines examined in vitro. The MCIDFs of MKN-45 and TMK-1 reflected their $\mathrm{IC}_{50} \mathrm{~s}$ for all three antineoplastic agents. 
MCIDF may be a marker of sensitivity in vitro. However, DNA fragmentation was observed in small pieces of tumors after culturing for $24 \mathrm{~h}$, even without exposure to antineoplastic agents. Some stromal cells surrounding the cancer cells were TUNEL-positive. This may account for DNA fragmentation in untreated small specimens. These results suggest that it is very difficult to assess chemosensitivity by examining MCIDF in small pieces of tumors containing both cancer and stromal cells.

Although TUNEL positivity did not show a clear dose-dependent increase in some cases, it did increase after treatment with DXR, SN-38, and Taxol. MKN-1 did not show DNA fragmentation in vitro and its TUNEL positivity was the lowest in the presence of all three antineoplastic agents. CDDP and 5-FU did not induce DNA fragmentation in vitro, and did not increase the number of TUNEL-positive cells. Complete evaluation of the number of TUNEL-positive cells at three different drug concentrations indicated differences in the level of apoptosis induced by each antineoplastic agent tested for each cancer cell line tested.

Meyn et al. [19] reported a dose-dependent increase in apoptosis detectable by morphological changes in transplanted ovarian and mammary adenocarcinomas treated with CDDP in vivo. The dose-response relationship for CDDP-induced apoptosis correlated with the tumor response. In the present study, the percentage of TUNEL-positive cancer cells correlated with $\mathrm{IC}_{50}$ in the presence of DXR, SN-38, and Taxol. MKN-45 exhibited the highest TUNEL positivity and showed the highest response to Taxol in an animal model. The percentage of TUNEL-positive cells detectable after treatment with CDDP or 5-FU did not show a dose-dependent increase for any of the three cancers tested. TUNEL positivity did not appear to reflect chemosensitivity for CDDP and 5-FU (data not shown). Because apoptosis is not the only mechanism reflecting the antitumor effects of drugs, low TUNEL positivity may not reflect resistance to antineoplastic agents. This may explain the discrepancy between the results for MKN-1 and TMK1 obtained in the animal model and the TUNEL assay. The results for MKN-45 obtained in the animal model and TUNEL assay suggest that high TUNEL positivity in small pieces of tumors may serve as a marker of high sensitivity to antineoplastic agents when apoptosis is implicated. However, TUNEL positivity cannot detect chemoresistance.

The expression of markers such as $p 53[20,21]$ and bcl-2 [22,23] has been shown to be associated with apoptosis. Because MKN-1 and TMK-1 have point mutations in p53, while MKN-45 has wild-type p53 [24], it is possible that the status of $p 53$ is related to TUNEL positivity and sensitivity to DXR, SN-38, and Taxol. However, Wahl et al. [25] reported that mutant p53 enhanced sensitivity to Taxol, and the relationship between $p 53$ and chemosensitivity has been reported to depend on the cell type, the antineoplastic agent, the treatment schedule, and the cell cycle. Our methods for assessing chemosensitivity may evaluate antitumor effects more directly than via the status of these genes.

\section{Conclusion}

TUNEL positivity in small cancer specimens after exposure to antineoplastic agents reflects chemosensitivity when apoptosis is implicated. Our test for chemosensitivity requires only small specimens that can be obtained by biopsy and may be applicable to chemosensitivity testing clinically. The clinical utility of this method should be investigated in a future prospective study.

Acknowledgments This study was supported, in part, by a Grant-in-Aid for Cancer Research (6-1) from the Ministry of Health and Welfare of Japan.

\section{References}

1. Kern DH, Weisenthal LM. Highly specific prediction of antineoplastic drug resistance with an in vitro assay using suprapharmacologic drug exposures. J Natl Cancer Inst 1990;82:5828.

2. Salmon ES, Hamburger AW, Soehnlen B, Durie BGM, Alberts DS, Moon TE. Quantitation of differential sensitivity of humantumor stem cells to anticancer drug. N Engl J Med 1978;298:13217.

3. Vescio RA, Connors KM, Kubota T, Hoffman RM. Correlation of histology and drug response of human tumors grown in nativestate three-dimensional histoculture and in nude mice. Proc Natl Acad Sci USA 1991;88:5163-6.

4. Gazdar AF, Steinberg SM, Russel EK, Linnoila RI, Oie HK, Ghosh BC, et al. Correlation of in vitro drug-sensitivity testing results with response to chemotherapy and survival in extensivestage small cell lung cancer: a prospective clinical trial. J Natl Cancer Inst 1990;82:117-24.

5. Kubota T, Nobuaki S, Abe O, Nakao I, Kawahara E, Saito T, et al. Potential of histoculture drug assay to cancer patient survival. Clin Cancer Res 1995;1:1537-43.

6. Von Hoff DD, Clark GM, Stogdill BJ, Sarosdy MF, O'Brien MT, Casper JT, et al. Prospective clinical trial of a human tumor cloning system. Cancer Res 1983;43:1926-31.

7. Von Hoff DD, Sandbach JF, Clark GM, Turner JN, Forseth BF, Piccart MJ, et al. Selection of cancer chemotherapy for a patient by in vitro assay versus a clinician. J Natl Cancer Inst 1990;82:11016.

8. Chang YF, Li LL, Wu CW, Liu TY, Lui WY, P'eng FK, et al. Paclitaxel-induced apoptosis in human gastric carcinoma cell lines. 1996; Cancer 77:14-18.

9. Cotter TG, Glynn JM, Echeverri F. The induction of apoptosis by chemotherapeutic agents occurs in all phases of the cell cycle. Anticancer Res 1992;12:773-9.

10. Eastman A. Activation of programmed cell death by anticancer agents: cisplatin as a model system. Cancer Cells 1990;2:27580 . 
11. Hickman JA. Apoptosis induced by anticancer drugs. Cancer Metastasis Rev 1992;11:121-39.

12. Kaufmann SH. Induction of endonucleolytic DNA cleavage in human acute myelogeneous leukemia cells by etoposide, camptothecin and other cytotoxic anti-cancer drugs: a cautionary note. Cancer Res 1989;49:5870-8.

13. Ohmori T, Podack ER, Nishio K, Takahashi M, Miyahara Y, Takeda Y, et al. Apoptosis of lung cancer cells caused by some anti-cancer agents (MMC, CPT-11, ADM) is inhibited by bcl-2. Biochem Biophys Res Commun 1993;192:30-6.

14. Yael G, Sherman Y, Ben-Sasson SA. Identification of programmed cell death in situ via specific labeling of nuclear DNA fragmentation. J Cell Biol 1992;119:493-501.

15. Milross CG, Mason KA, Hunter NR, Chung WK, Peters LJ, Milas L. Relationship of mitotic arrest and apoptosis to anticancer effect of paclitaxel. J Natl Cancer Inst 1996;88:130814.

16. Wu GS, El-Deiry WS. Apoptotic death of tumor cells correlates with chemosensitivity, independent of p53 or bcl-2. Clin Cancer Res 1996;2:623-33.

17. Motoyama T, Hojo H, Watanabe $\mathrm{H}$. Comparison of seven cell lines derived from human gastric carcinomas. Acta Pathol Jpn 1986;36:65-83.

18. Ochiai A, Yasui W, Tahara E. Growth-promoting effect of gastrin on human gastric cancer cell line TMK-1. Jpn J Cancer Res 1985; 76:1064-71.
19. Meyn RE, Stephens LC, Hunter NR, Milas R. Kinetics of cisplatin-induced apoptosis in murine mammary and ovarian adenocarcinomas. Int J Cancer 1995;60:725-9.

20. Lotem J, Sachs L. Regulation by bcl-2, c-myc, and p53 of susceptibility to induction of apoptosis by heat shock and cancer chemotherapy compounds in differentiation-competent and -defective myeloid leukemic cells. Cell Growth Differ 1993;4:41-7.

21. Lowe SW, Ruley HE, Jacks T, Houseman DE. p53-Dependent apoptosis modulates the cytotoxicity of anticancer agents. Cell 1993;74:957-67.

22. Hsu B, Marin MC, Brisbay S, McConnell K, McDonnell TJ. Expression of bcl-2 gene confers multidrug resistance to chemotherapy-induced cell death. Cancer Bull 1994;46:1259.

23. Miyashita T, Reed JC. bcl-2 Gene transfer increases relative resistance of S49.1 and WEHI7.2 lymphoid cells to cell death and DNA fragmentation induced by glucocorticoids and multiple chemotherapeutic drugs. Cancer Res 1992;52:5407-11.

24. Yamada Y, Yoshida T, Hayashi K, Sekiya T, Yokota J, Hirohashi $\mathrm{S}$, et al. p53 Gene mutation in gastric cancer metastases and in gastric cancer cell lines derived from metastases. Cancer Res 1991;51:5800-5.

25. Wahl AF, Donaldson KL, Fairchild C, Lee FY, Foster SA, Demers GW, et al. Loss of normal p53 function confers sensitization to Taxol by increasing G2/M arrest and apoptosis. Nature Med 1996;2:72-9. 